\title{
O Impacto da Pobreza Multidimensional e da Desigualdade na Distribuição de Renda nos Fluxos Migratórios, 1991, 2000 e 2010: Uma Abordagem Espacial para os Municipios Brasileiros
}

\author{
Marcos Aurélio Brambilla $^{1}$ (D) | Marina Silva da Cunha ${ }^{2}$ (ID \\ ${ }^{1}$ Universidade Estadual de Maringá. E-mail: marcos-brambilla@hotmail.com \\ ${ }^{2}$ Universidade Estadual de Maringá. E-mail: mscunha@uem.br
}

\begin{abstract}
RESUMO
O objetivo do presente estudo foi avaliar a distribuição espacial dos fluxos migratórios nos municípios e o impacto da pobreza e da desigualdade na distribuição de renda na taxa líquida de migração, com base nas informações dos Censos Demográficos dos anos de 1991, 2000 e 2010. Para tanto, foi utilizada a abordagem de econometria espacial. Os resultados indicaram que em todo o período houve maior concentração de fluxos migratórios no estado de São Paulo e na região Centro-Oeste e menor incidência no estado de Minas Gerais e na região Nordeste. Além disso, o estudo indicou que a pobreza multidimensional, a desigualdade na distribuição de renda, a pobreza multidimensional dos municípios vizinhos e a desigualdade na distribuição de renda dos municípios vizinhos apresentaram impacto negativo sobre a taxa de migração, sendo que, entre os determinantes estudados, a pobreza multidimensional apresentou o maior impacto na decisão de migração do indivíduo.
\end{abstract}

\section{PALAVRAS-CHAVE}

Migração, Pobreza multidimensional, Desigualdade na distribuição de renda, Econometria espacial

The Impact of Multidimensional Poverty and Inequality in Income Distribution in Migration Flows, 1991, 2000 and 2010: A Spatial Approach for Brazilian Municipalities

\begin{abstract}
The objective of the present study was to evaluate the spatial distribution of migratory flows in municipalities and the impact of poverty and income inequality on the net migration rate, based on information from the Demographic Census of 1991, 2000 and 2010. For this, the spatial econometrics approach was used. The results indicated that during the whole period, there was a higher concentration of migratory flows in the state of São Paulo and in the Center-West region and lower incidence in the state of Minas Gerais and in the Northeast region. In addition, the study indicated that multidimensional poverty, income inequality, multidimensional poverty of neighboring municipalities, and inequality in the income distribution of neighboring municipalities had a negative impact on the migration rate. Given that, among the determinants studied, multidimensional poverty had the greatest impact on the individual's decision to migrate.
\end{abstract}

KEYWORDS

Migration, Multidimensional Poverty, Income inequality, Spatial econometrics

\section{CLASSIFICAÇÃO JEL} R23 


\section{Introdução}

A migração é um tema de grande relevância na literatura econômica, pois influencia tanto as localidades de origem dos migrantes quanto os lugares de destino. Em países em desenvolvimento, como o Brasil, a imigração foi mais intensa no final do século XIX (Abreu e Lago, 2010). Porém, o Brasil se tornou um país urbanizado apenas no final do século $\mathrm{XX}^{1}$, ou seja, com a maior parte da população vivendo nas cidades. O principal fator foi o êxodo rural ocorrido nesse período, principalmente para os grandes centros urbanos. A partir da década de 1990, houve uma mudança na dinâmica migratória, com o processo migratório interno nas áreas urbanas, no qual as grandes cidades diminuíram seu poder de atração e outras cidades, de porte médio, também começaram a atrair um número significativo de imigrantes (Golgher et al., 2004).

A decisão de migrar está pautada nas características favoráveis do município de destino, considerando que o indivíduo busca melhor qualidade de vida. No entanto, os migrantes têm que arcar com custos monetários e não monetários. Nesse sentido, a migração pode ser correlacionada com o grau de instrução do indivíduo (Sjaastad, 1962). A migração também pode ser imposta para os indivíduos por questões políticas, religiosas e/ou naturais (Golgher et al., 2004), ou ainda pode ser incentivada pelos diferenciais de rendimentos entre as regiões (Sahota, 1968; Cooper, 1994). Conforme a literatura empírica, dois dos principais motivos para o indivíduo migrar são: busca por uma melhor qualidade de vida e questões econômicas (Pekkala, 2003; Justo e Silveira Neto, 2006; Da Mata et al., 2008; Kim e Cohen, 2010; Etzo, 2011; Ramalho e Queiroz, 2011; Gama e Machado, 2014). Além disso, outro fator relevante que contribui para explicar a decisão de o indivíduo migrar é o espaço, ou seja, as regiões vizinhas, mas em geral limita a representá-lo de forma simplificada, com alguma medida de distância geográfica ou custos de transporte entre regiões (Cushing e Poot, 2004; Justo e Silveira Neto, 2006).

Diante disso, os fatores de qualidade de vida que podem ser observados para que o indivíduo seja estimulado a migrar podem ser encontrados em uma variável multidimensional. Na literatura, é consolidada a pobreza multidimensional, sendo assim, como essa variável leva em consideração fatores relacionados ao bem-estar de uma população, como saúde e saneamento, educação, condições de moradia e mercado de trabalho, ela pode apresentar a qualidade de vida de uma determinada região.

Desse modo, este estudo busca contribuir com a análise dos fluxos migratórios a nível municipal. Diante desse contexto, surgem as seguintes indagações: quais são as regiões com maior e menor concentração de fluxos migratórios? Qual é o impacto da pobreza e da desigualdade na distribuição de renda nos fluxos migratórios? Portanto, o objetivo do presente estudo foi analisar a distribuição espacial dos fluxos migratórios

\footnotetext{
${ }^{1}$ De acordo com Simoes (2016), o Brasil apresentou a maior parte da população vivendo na área rural até 1960, sendo que o Censo Demográfico de 1960 indicava uma taxa de urbanização de 45\%, enquanto o Censo Demográfico de 1970 indicava uma taxa de urbanização de 56\%.
} 
nos municípios brasileiros considerando as Áreas Minimamente Comparáveis (AMC) e o impacto da pobreza e da desigualdade na distribuição de renda nos fluxos migratórios nos anos de 1991, 2000 e 2010. Foram considerados todos os 4267 municípios para o ano de 1991.

Ademais, este estudo procura contribuir para a literatura por meio da construção dos fluxos migratórios interestaduais e das demais variáveis por municípios considerando as Áreas Minimamente Comparáveis (AMC) referentes ao ano de 1991 para a uniformização dos dados. Mais especificamente, buscou-se a estimativa de um modelo de painel de dados com dependência espacial a nível municipal para obter coeficientes mais eficientes e uma avaliação do impacto da pobreza, mensurada tanto pela perspectiva da renda quanto multidimensional sobre a Taxa Líquida de Migração.

Para isso, este estudo foi dividido em seis seções, incluindo esta introdução. A segunda seção aborda os aspectos teóricos e empíricos sobre os fluxos migratórios. A terceira seção exibe os procedimentos metodológicos. A quarta seção apresenta a evolução da distribuição espacial dos fluxos migratórios. A quinta seção apresenta os resultados e as discussões das estimativas; e a sexta seção exibe as considerações finais.

\section{Aspectos teóricos e empiricos acerca da migração}

Nos trabalhos de migração, um dos primeiros passos é definir migração. No entanto, essa não é uma tarefa simples, visto que o ato de migrar se refere ao indivíduo que muda de residência, porém ele pode mudar de residência em um mesmo município com uma distância muito maior do que outro indivíduo que mudou de país. Um migrante tem uma origem e um local de destino. Para o lugar de origem, o indivíduo é um emigrante e para o lugar de destino é um imigrante (Golgher et al., 2004).

A literatura considera diferentes formas de migração. Migração externa (Borjas, 1987; Massey, 1999; Mayda, 2010; Kim e Cohen, 2010) refere-se à migração internacional, entre países. Na migração interna, existe mais de um tipo de migração, a migração inter-regional (Etzo, 2011), entre regiões; a migração interestadual (Sahota, 1968; Mueser, 1989; Pekkala, 2003; Justo e Silveira Neto, 2006; Hunt, 2006; Ramalho e Queiroz, 2011; Maciel e Cunha, 2013), entre Unidades da Federação (UF); a migração intermesorregional, entre mesorregiões; e a migração intermunicipal (Da Mata et al., 2008; Gama e Machado, 2014), entre municípios.

Além disso, alguns estudos também apresentam outras três classificações de migração. A partir de uma migração interestadual, as classificações são relacionadas aos migrantes, os quais representam os indivíduos que residem em uma UF diferente de sua naturalidade. Migrantes de retorno representam os indivíduos que residem na mesma UF do seu nascimento, porém já residiram em outra UF. Não migrantes é a classificação que representa os indivíduos que residem na mesma UF de sua naturalidade e que nunca moraram em outra UF (Olesen, 2002; Pekkala, 2003; Ramalho e 
Queiroz, 2011; Gama e Machado, 2014).

Outro conceito utilizado na literatura é a Taxa Líquida de Migração, que representa a diferença entre taxa de imigração e taxa de emigração (Pekkala, 2003; Justo e Silveira Neto, 2006; Mueser, 1989; Da Mata et al., 2008; Etzo, 2011). Estudos procuram explicar a migração interestadual, especialmente em países com dimensões continentais como o Brasil. Na figura a seguir, é possível observar a imigração, a emigração e os fluxos migratórios interestaduais brasileiros por Unidade da Federação em 1991, 2000 e 2010, sendo que as cores mais escuras representam os maiores percentuais.

Figura 1. Mapa da distribuição espacial da imigração, da emigração e da migração líquida no Brasil por UF, 1991, 2000 e 2010
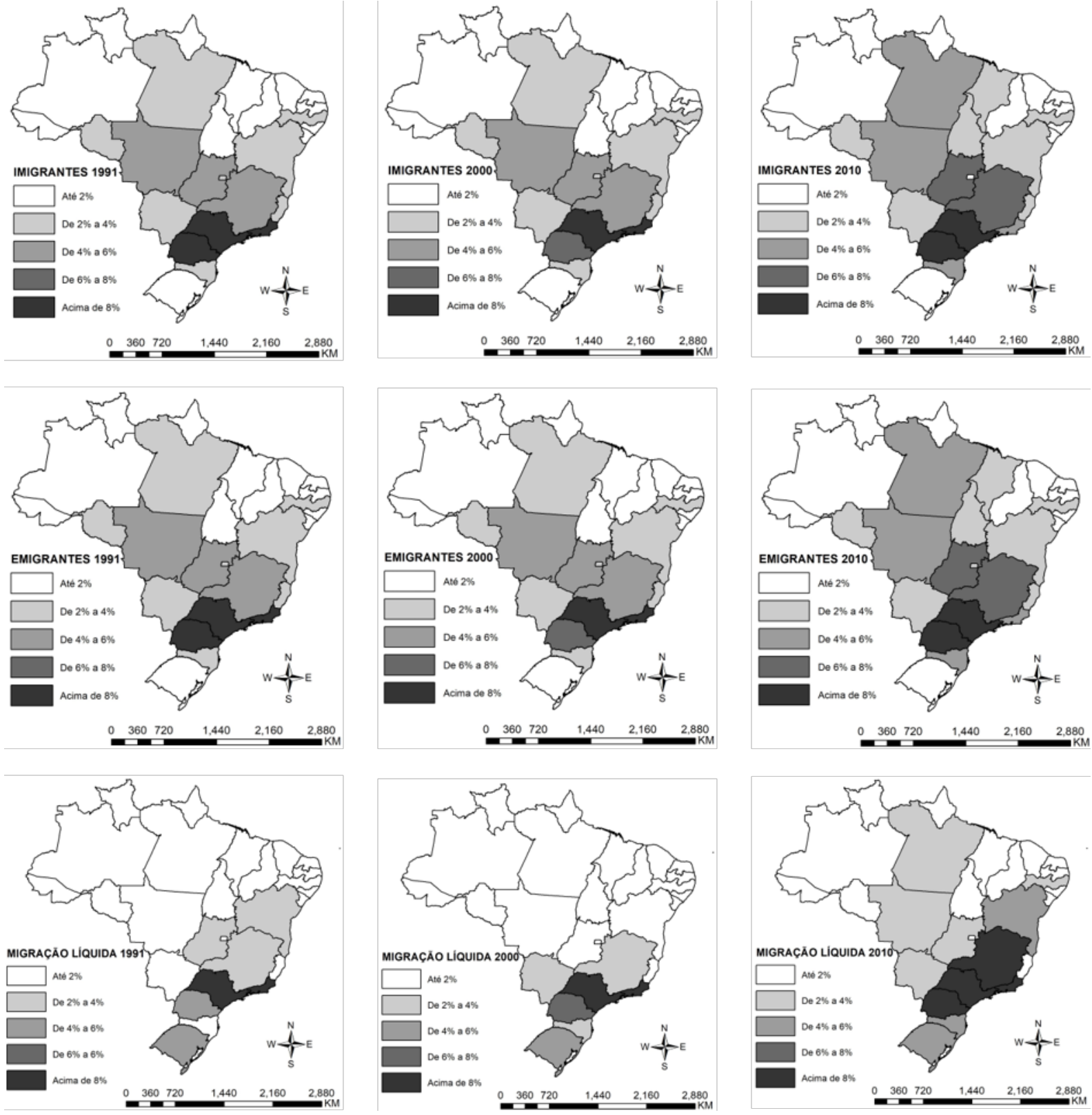

Fonte: Elaboração própria a partir dos dados da pesquisa. 
Como observado na Figura 01, a imigração ocorreu principalmente no estado de São Paulo, que apresentou o maior percentual nos três períodos. Os estados do Paraná e Rio de Janeiro também se destacam por apresentarem a maior classificação de imigrantes em dois anos do período. Por outro lado, as regiões Norte e Nordeste apresentaram a maioria dos estados nos três anos com menos de $2 \%$ de imigrantes.

Observa-se, pela taxa de migração, que, até os anos 2000, poucos estados apresentavam altas taxas de migração, com destaque para São Paulo e Rio de Janeiro, pois os imigrantes se deslocavam para esses estados em busca de melhor qualidade de vida e de emprego. Em 2010, ocorreu um aumento da taxa de migração em outras regiões: além de São Paulo e Rio de Janeiro, Paraná e Minas Gerais se destacaram no cenário nacional e os outros estados das regiões Sul, Sudeste e Centro-Oeste também aumentaram as taxas de migração, o que pode ser explicado pelo desenvolvimento dessas regiões no período.

Deve ser destacado que a taxa de emigrantes, ou seja, a proporção da população que deixou a UF, apresentou a mesma característica da taxa de imigração, com destaque para São Paulo, Rio de Janeiro e Paraná, cuja taxa de emigração ficou acima de $8 \%$, e a maioria dos estados do Norte e Nordeste, com uma taxa de emigração menor.

Os estados de São Paulo e Rio de Janeiro se destacaram por apresentar, nos três anos, o maior percentual do saldo migratório. Por outro lado, a região Norte apresentou o pior resultado nos fluxos migratórios, com todos os estados apresentando uma taxa líquida de migração de menos de $2 \%$ nos de 1991 e 2000, e, em 2010, apenas o estado do Pará não apresentou esse percentual, mantendo uma taxa de migração líquida de $2 \%$ a $4 \%$.

Para a literatura empírica, estes são os principais motivos para um indivíduo migrar: busca por uma melhor qualidade de vida e/ou questões econômicas. Portanto, uma variável econômica relevante que influencia negativamente os fluxos migratórios é o índice de Gini (Justo e Silveira Neto, 2006; Da Mata et al., 2008). Outro fator que pode apresentar impacto negativo sobre os fluxos migratórios é a pobreza multidimensional, pois engloba variáveis de qualidade de vida e econômica, porém ainda não foi utilizada pela literatura empírica pesquisada.

Além dessas variáveis, são utilizadas outras variáveis explicativas como taxa de urbanização (Kim e Cohen, 2010; Ramalho e Queiroz, 201 1), densidade populacional (Da Mata et al., 2008; Kim e Cohen, 2010; Etzo, 2011), distância da capital (Pekkala, 2003; Kim e Cohen, 2010; Etzo, 2011) e renda per capita (Justo e Silveira Neto, 2006; Gama e Machado, 2014), pois quanto mais pessoas na área rural, mais pessoas por quilômetro quadrado, quanto menor for a distância da capital e quanto maior for a renda per capita, maior é a possibilidade de atração de imigrantes. 


\section{Procedimentos metodológicos}

\subsection{Fonte de dados, indicador de migração e Índice de Pobreza Multidi- mensional}

Os dados utilizados neste trabalho foram coletados dos Censos Demográficos do Instituto Brasileiro de Geografia e Estatística (IBGE) de 1991, 2000 e 2010. De acordo com os Censos entre 1991 e 2010, foram criados 1.074 municípios. Conforme Favero (2004), até o ano 2000, além de ocorrerem emancipações a partir de um município, houve municipios que se emanciparam a partir de dois ou mais municípios.

Portanto, os municípios utilizados foram representados pelas Áreas Minimamente Comparáveis (AMC), que representam cada uma das regiões onde foram realizadas as emancipações entre 1991 e 2010 e os demais municípios. O estudo de Magalhães (2007) mostra as emancipações entre 1991 e 2000, enquanto o trabalho do IPEA (2010) ilustra as emancipações de 2000 a 2010. Com isso, foi possível realizar a uniformização dos dados nos três períodos para a realização da análise espacial, para assim obter a mesma quantidade de unidades espaciais, como é realizado na literatura (Andrade et al., 2004; Coelho e Figueiredo, 2007). Desse modo, o estudo abrangeu 4267 municípios referentes ao ano de 1991, totalizando 12.801 observações nos três anos.

A decisão do indivíduo de migrar está pautada nas características do município de origem (Da Mata et al., 2008), este estudo abrange as informações de fluxos migratórios a nível municipal. No entanto, não há informações para a construção da variável com migrações intermunicipais, pois não é possível verificar a migração de todos os municípios por utilizar no modelo as AMC referentes a 1991. Desse modo, foram consideradas as migrações interestaduais por município.

Para a construção da variável de migração, foram utilizadas as variáveis de taxa de imigração (IMIGRA) e taxa de emigração (IMIGRA). A taxa de imigração foi representa pelo percentual da população dos municípios que nasceu em outras Unidades da Federação. A taxa de emigração representa o percentual da população dos municípios que saiu da Unidade da Federação de origem. Portanto, foi construída a variável de Taxa Líquida de Migração (MIGRA), representada pela diferença entre a taxa de imigração e taxa de emigração (Pekkala, 2003; Justo e Silveira Neto, 2006; Mueser, 1989; Da Mata et al., 2008; Etzo, 2011).

No Guadro 1, estão apresentadas as seis dimensões utilizadas, os vinte componentes e os trinta e quatro indicadores referentes às privações dos indivíduos e domicílios, utilizadas na construção do Índice de Pobreza Multidimensional (IPM), obtido a partir da literatura empírica sobre o tema, em especial Barros et al. (2006) e Albuquerque e Cunha (2012). 
Guadro 1. Dimensões, componentes e indicadores que compõem o Îndice de Pobreza Multidimensional

\begin{tabular}{|c|c|}
\hline Componentes & Indicadores \\
\hline \multicolumn{2}{|c|}{ Dimensão 1: Saúde e Saneamento } \\
\hline Abastecimento de água & S1: Abastecimento de água inadequado \\
\hline Coleta de lixo & S2: Lixo não é coletado \\
\hline Esgoto sanitário & S3: Esgoto sanitário inadequado \\
\hline Condição sanitária & S4: Domicílios sem banheiro \\
\hline \multirow{3}{*}{ Mortalidade infantil } & S5: Existência de algum filho nascido vivo que morreu \\
\hline & $\begin{array}{l}\text { S6: Domicílio com pelo menos uma criança até } 1 \text { ano de idade que } \\
\text { tenha falecido }\end{array}$ \\
\hline & $\begin{array}{l}\text { S7: Domicílio com pelo menos uma criança até } 5 \text { anos de idade que } \\
\text { tenha falecido }\end{array}$ \\
\hline \multicolumn{2}{|l|}{ Dimensão 2: Educação } \\
\hline \multirow{3}{*}{ Analfabetismo } & E1: Presença de ao menos um adolescente de 10 a 14 anos analfabeto \\
\hline & E2: Presença de ao menos um jovem de 15 a 17 anos analfabeto \\
\hline & E3: Presença de pessoas de 18 anos ou mais analfabetas \\
\hline \multirow{4}{*}{ Escolaridade } & $\begin{array}{l}\text { E4: Ausência de algum membro da família que completou cinco } \\
\text { anos de estudo }\end{array}$ \\
\hline & E5: Ausência de adulto com ensino fundamental completo \\
\hline & E6: Ausência de adulto com ensino médio completo \\
\hline & E7: Ausência de adulto com ensino superior completo \\
\hline \multirow{3}{*}{ Acesso à escola } & $\begin{array}{l}\text { E8: Presença de criança fora da escola de } 7 \text { a } 17 \text { anos na } \\
\text { educação básica }\end{array}$ \\
\hline & $\begin{array}{l}\text { E9: Presença de criança fora da escola de } 7 \text { a } 14 \text { anos no } \\
\text { ensino fundamental }\end{array}$ \\
\hline & E10: Presença de criança fora da escola de 0 a 6 anos na pré-escola \\
\hline \multirow{2}{*}{ Progresso escolar } & E11: Presença de criança de até 14 anos com ao menos 2 anos de atraso \\
\hline & E12: Presença de criança de 15 a 18 anos com ao menos 2 anos de atraso \\
\hline \multicolumn{2}{|c|}{ Dimensão 3: Condição de Habitação } \\
\hline \multirow{2}{*}{ Propriedade } & H1: Domicílio não é próprio \\
\hline & H2: Domicílio não é próprio e nem cedido \\
\hline Energia elétrica & H3: Domicílios sem acesso à eletricidade \\
\hline Déficit habitacional & H4: Densidade de moradores por dormitório maior que 3 \\
\hline \multirow{2}{*}{ Informação } & H5: Não tem ao menos um dos itens: rádio ou televisão \\
\hline & H6: Não tem ao menos um dos itens: rádio, televisão ou telefone \\
\hline Bens & $\begin{array}{l}\text { H7: Não tem ao menos um dos itens: geladeira ou máquina } \\
\text { de lavar roupa }\end{array}$ \\
\hline \multicolumn{2}{|l|}{ Dimensão 4: Trabalho } \\
\hline \multirow{3}{*}{ Ocupação } & T1: Presença de adulto desempregado \\
\hline & T2: Ausência de ocupado no setor formal \\
\hline & $\begin{array}{l}\text { T3: Menos da metade dos membros em idade ativa encontram-se } \\
\text { ocupados }\end{array}$ \\
\hline Trabalho infantil & T4: Presença de trabalho infantil \\
\hline \multicolumn{2}{|l|}{ Dimensão 5: Renda } \\
\hline Pobreza & R1: Domicílio pobre \\
\hline Extrema pobreza & R2: Domicílio extremamente pobre \\
\hline \multicolumn{2}{|c|}{ Dimensão 6: Demografica } \\
\hline Idoso & $\begin{array}{l}\text { D1: Presença de idoso no domicílio (que não recebe aposentadoria } \\
\text { ou pensão) }\end{array}$ \\
\hline Cônjuge & D2: Ausência de cônjuge \\
\hline
\end{tabular}


Os indicadores foram compostos pela taxa de cada privação nos municípios. Dadas as informações para a construção do índice, para Barros et al. (2006), os pesos devem ser atribuídos de acordo com as preferências da sociedade. No entanto, não há um conhecimento dessas preferências. Diante dessa dificuldade e seguindo a literatura, para mensurar as preferências, foram atribuídos pesos idênticos para a construção dos indicadores, sendo que a construção do IPM segue a Equação 1.

$$
I P M=\frac{1}{6} \sum_{k=1}^{6}\left(\frac{1}{n_{k}} \sum_{j=1}^{n_{k}}\left(\frac{1}{m_{k}} \sum_{j=1}^{m_{j k}} \beta_{j i k}\right)\right)
$$

em que $\beta_{j i k}$ representa o $j$-ésimo indicador básico do $i$-ésimo componente da $k$-ésima dimensão, $n_{k}$ o número de componentes da $k$-ésima dimensão, e $m_{j k}$ o número de indicadores do $j$-ésimo componente da $k$-ésima dimensão. Para a construção do IPM, o primeiro passo foi atribuir aos indicadores pesos iguais para formação dos componentes. Após a construção dos componentes, no segundo passo, foram atribuídos aos componentes pesos iguais para a formação das dimensões e, posteriormente à construção das dimensões, no terceiro passo, foram atribuídos às dimensões pesos iguais para a construção do IPM.

\section{Método: econometria espacial}

Inicialmente, será utilizada a análise exploratória de dados espaciais (AEDE), é uma técnica para descrever e visualizar distribuições espaciais, identificar localidades atípicas (outliers espaciais), descobrir padrões de associação espacial (clusters espaciais) e sugerir diferentes regimes espaciais e outras formas de instabilidade, sendo consolidada na literatura (Anselin, 2013, 1995).

Modelos de painel de dados com dependência espacial

Segundo Druska e Horrace (2004), os modelos econométricos espaciais são uma extensão da econometria clássica que utiliza a localização no território como um dos fatores explicativos nos modelos. No presente estudo, serão utilizados os modelos de painel de dados com dependência espacial, sendo que serão avaliados os modelos de efeitos fixos e aleatórios com dependência espacial e o modelo de painel dinâmico espacial. Para a escolha do melhor modelo, foram testados o Modelo de Defasagem Espacial (SAR), o Modelo de Erro Autorregressivo Espacial (SEM), o Modelo Regressivo Cruzado Espacial (SLX), o Modelo Espacial de Durbin (SDM) e o modelo de Erro de Durbin (SDEM).

O modelo de painel de dados convencional de efeitos fixos, com dados empilhados, pode ser especificado como:

$$
y_{i t}=\alpha+\beta X_{i t}+\varepsilon_{i t}
$$


em que $y_{i j}$ representa a variável dependente, $\alpha$ é um vetor que denota os efeitos fixos, $X_{i t}$ representa as variáveis exógenas do modelo e $\varepsilon_{i t}$ representa o termo de erro, sendo idêntica e independentemente distribuído (i.i.d), com média zero e variância constante, e $\beta$ é um vetor de coeficientes que acompanha as variáveis exógenas.

O modelo de efeitos aleatórios considera os efeitos não observáveis e invariantes no tempo, sendo específicos à região, não como sendo fixos, mas como sendo uma variável aleatória. Sendo assim, o modelo de efeitos aleatórios, com dados empilhados, pode ser representado por:

$$
y_{i t}=\beta X_{i t}+\xi_{i t}
$$

Agora, o componente específico $\alpha$ foi incluído no erro:

$$
\xi_{i t}=\alpha+\varepsilon_{i t}
$$

em que $\alpha\left(0, \sigma_{i, t}^{2}\right)$ corresponde a um componente do erro aleatório, o qual varia através das regiões, porém é constante.

Modelo de Defasagem Espacial (Spatial Lag Model - SAR)

O Modelo de Defasagem Espacial (SAR) informa que a variável dependente y é influenciada pela variável dependente das regiões vizinhas $\left(W y_{i t}\right)$. Devido à multidirecionalidade da dependência espacial, a variável $W y_{i t}$ é endógena, implicando que os valores de $y$ nas regiões vizinhas influenciam a variável dependente em um processo de causação circular (LeSage e Pace, 2014; Elhorst, 2014). O modelo SAR pode ser represento pela Equação 5:

$$
y_{i t}=\rho W y_{i t}+\beta X_{i t}+\varepsilon_{i t}
$$

em que $\rho$ é o coeficiente que acompanha a variável dependente defasada $W y_{i t}$.

Modelo de Erro Autorregressivo Espacial (Spatial Error Model - SEM)

O modelo SEM tem como principal vantagem em relação a modelos de defasagem espacial, como o SAR, o fato de evitar a verificação de viés nas estimativas. Como os modelos de defasagem espacial possuem forte correlação entre as variáveis dependentes e sua defasagem espacial, podem ocorrer problemas de consistência pela convergência tanto do valor esperado da variável dependente quanto da matriz de covariância das explicativas para uma mesma estimativa. O modelo SEM, por especificar a dependência espacial apenas no termo de erro, evita problemas de consistência, ocorrendo apenas o risco de problemas de eficiência, assumidos como preferíveis aos primeiros pela literatura econométrica (Pace e Zhu, 2012). 
Nesse modelo, a dependência espacial é residual, caracterizada pela estrutura autorregressiva de primeira ordem no termo de erro. O modelo de erro autorregressivo espacial é dado pela Equação 7:

$$
\begin{gathered}
y_{i t}=\beta X_{i t}+\mu_{i t} \\
\mu_{i t}=\lambda W \mu_{i t}+\varepsilon_{i t}
\end{gathered}
$$

em que $\lambda$ é o coeficiente do parâmetro do erro autorregressivo espacial que acompanha a defasagem $W \mu_{i t}$.

Modelo Regressivo Cruzado Espacial (Spatial Lag of X-SLX)

O modelo regressivo cruzado agrega no modelo a defasagem das variáveis explicativas. Porém, essas podem estar correlacionadas com a variável dependente defasada. Caso isso ocorra, o modelo mais indicado é o modelo espacial de Durbin, que será apresentado a seguir. Com relação à omissão da variável dependente defasada, os resultados das estimativas serão viesados e inconsistentes (Elhorst, 2014). O modelo formal pode ser apresentado pela Equação 8:

$$
y_{i t}=\beta X_{i t}+\tau W X_{i t}+\varepsilon_{i t}
$$

em que $\tau W X_{i t}$ representa as defasagens espaciais das variáveis explicativas do modelo.

Modelo Espacial de Durbin (Spatial Durbin Model - SDM)

O modelo Durbin espacial tem tanto um alcance global dado pelo multiplicador espacial que surge em decorrência da presença da variável dependente defasada especialmente quanto um alcance localizado dado pelas defasagens espaciais das variáveis explicativas. O modelo espacial Durbin pode ser representado pela Equação 9:

$$
y_{i t}=\rho W y_{i t}+\beta X_{i t}+\tau W X_{i t}+\varepsilon_{i t}
$$

O modelo espacial de Durbin, além de incorporar a ideia do transbordamento por meio de defasagem das variáveis independentes $\left(W X_{i t}\right)$, incorpora a suposição de que existiria um processo de difusão que influencia a variável dependente, ou algum outro fenômeno que justificasse a inclusão da variável endógena defasada espacialmente $\left(W y_{i t}\right)$ (LeSage e Pace, 2014).

Modelo de Erro Espacial de Durbin (Spatial Durbin Error Model - SDEM)

No modelo de erro espacial de Durbin, diferentemente do modelo espacial de Du- 
blin, além de incorporar as defasagens espaciais das variáveis explicativas, $\tau W X_{i t}$ incorpora a defasagem espacial do termo de erro $\lambda W \mu_{i t}$ (Elhorst, 2014) e pode ser representado formalmente pela Equação 10:

$$
\begin{gathered}
y_{i t}=\beta X_{i t}+\tau W X_{i t}+\mu_{i t} \\
\mu_{i t}=\lambda W \mu_{i t}+\varepsilon_{i t}
\end{gathered}
$$

Nos modelos apresentados, a variável dependente $y_{i t}$ foi representada pela Taxa Líquida de Migração (MIGRA), que corresponde à diferença entre os imigrantes interestaduais de cada município (corresponde ao percentual de pessoas no município que são de outras Unidades da Federação) e os emigrantes interestaduais de cada município (corresponde ao percentual de pessoas no município que foram para outras Unidades da Federação), e $X_{i t}$ representa as variáveis explicativas do modelo por município, sendo que as variáveis independentes do modelo representadas pela taxa de urbanização (TX_URB), pela densidade populacional (DENS_POP), pela proxy de distância inversa da capital ponderada pelo PIB estadual (DISTANCIA) ${ }^{2}$ e pela renda domiciliar per capita a cada R\$1.000,00 (REND_D_PC) apresentam relação positiva com a Taxa Líquida de Migração (MIGRA) (Sahota, 1968; Pekkala, 2003; Justo e Silveira Neto, 2006; Da Mata et al., 2008; Kim e Cohen, 2010; Mayda, 2010; Ramalho e Queiroz, 2011; Etzo, 2011; Maciel e Cunha, 2013; Gama e Machado, 2014), enquanto que o Índice de Pobreza Multidimensional (IPM) ${ }^{3}$ e o índice de Gini (GINI) estão inversamente relacionados com a migração (Sahota, 1968; Borjas, 1987; Justo e Silveira Neto, 2006; Da Mata et al., 2008).

Desse modo, o modelo foi apresentado seguindo os procedimentos sugeridos por Almeida (2012). Incialmente, foi realizado o teste Breuch-Pagan para verificar a presença de efeitos não observados. Posteriormente, foi realizado o teste de Hausman para a escolha do modelo (de efeitos fixos ou de efeitos aleatórios). Checada a autocorrelação espacial dos resíduos, foram estimados os modelos com efeitos espaciais comentados para painel de dados e em seguida foi verificado se houve a eliminação da dependência espacial. Por fim, o modelo espacial mais adequado é escolhido entre os modelos que não apresentaram dependência espacial nos resíduos, considerando a razão de verossimilhança (LIK) e os critérios de informação de Akaike (AIC) e Schwarz (BIC).

\footnotetext{
${ }^{2}$ Para a construção da variável proxy de distância inversa da capital ponderada pelo PIB estadual, foi normalizada entre 0 e 1 a distância inversa da capital dos municípios, subtraída por 1 e o resultado multiplicado pelo PIB estadual normalizado pelo maior PIB da amostra (PIB de São Paulo do ano de 2010).

${ }^{3} \mathrm{O}$ procedimento de estimação do Índice de Pobreza Multidimensional pode ser verificado na subseção 3.1 .
} 


\section{Distribuição e dependência espacial das taxas de imigra- ção, emigração e migração liquida}

Nesta seção, apresenta-se a evolução da distribuição espacial das taxas líquidas de migração, imigração e emigração para os anos de 1991, 2000 e 2010, realizada pela análise exploratória de dados espaciais (AEDE) para verificar a presença do padrão espacial dos fluxos migratórios por meio da taxa líquida de migração.

\subsection{Análise da distribuição espacial}

Na Figura 2 foi apresentada a distribuição espacial da imigração, da emigração e da migração líquida dos municípios brasileiros no período. As cores mais escuras apresentam os municípios com as maiores taxas de migração para os três indicadores.

Esses resultados sugerem um padrão na distribuição espacial das taxas de migração nos municípios nos três períodos. Os municípios com as maiores taxas de imigração e emigração nos três anos estão concentrados principalmente nas regiões Norte e Centro-Oeste. Por outro lado, a região Nordeste e os estados do Amazonas e do Rio Grande do Sul apresentaram a maior concentração de municípios com os menores indicadores de imigração e emigração.

Em relação à taxa líquida de migração, os municípios com maiores indicadores estão situados principalmente na região Centro-Oeste e no estado de São Paulo, enquanto os municípios com os menores fluxos migratórios estão concentrados principalmente na Região Nordeste. Além disso, foi identificado um aumento do fluxo migratório no período. No ano de 1991, as regiões Norte, Nordeste, Sudeste, Sul e Centro-Oeste apresentavam 10\%, 1\%, 19\%, 14\% e 19\% dos municipios nas duas maiores classificações da taxa líquida de migração e esses percentuais aumentaram para $29 \%$, 8\%, 34\%, 37\% e 56\%, no período, respectivamente.

Desse modo, apesar das evidências de que as três taxas de migração têm um padrão na distribuição espacial, foram realizados os procedimentos estatísticos da análise exploratória de dados espaciais para verificar o padrão espacial apenas da taxa líquida de migração, conforme os objetivos do estudo.

\subsection{Análise exploratória de dados espaciais}

Na Tabela 1 foi avaliado o indicador de autocorrelação espacial global para os três anos do período analisado para a taxa líquida de migração. Para a escolha da matriz de pesos espaciais, foram utilizadas as matrizes de convenção Rainha, Torre, K 6 vizinhos, $\mathrm{K} 8$ vizinhos e $\mathrm{K} 10$ vizinhos. 
Figura 2. Mapa da distribuição espacial da imigração, da emigração e da migração líquida no Brasil por município, 1991, 2000 e 2010
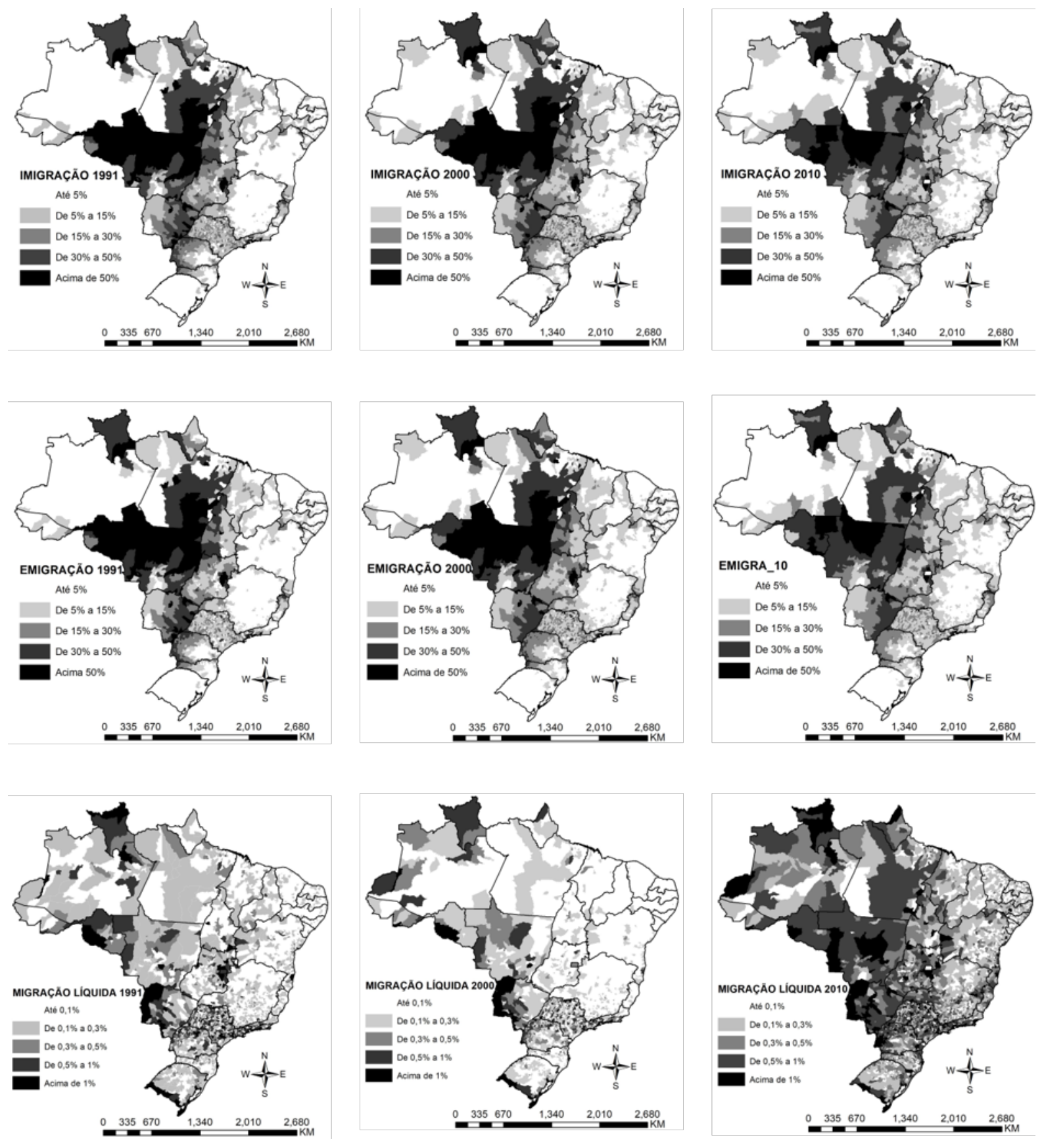

Fonte: Elaboração própria a partir dos dados da pesquisa.

O I de Moran esperado para os 4267 municípios é de e, assim, os valores com o $I$ de Moran são superiores ao $I$ de Moran esperado, $E(I)$, são significativos e sugerem autocorrelação espacial positiva. Pode ser observado, na tabela acima, que os valores do $I$ de Moran estimados dos três anos foram maiores do que $E(I)$, com nível de significância a 1\%. Desse modo, a taxa líquida de migração dos municípios brasileiros apresentou autocorrelação espacial positiva, indicando que os municípios com altos (baixos) fluxos migratórios são circunvizinhados por municípios com alta (baixa) taxa 
líquida de migração.

Tabela 1. Autocorrelacão global da MIGRA no Brasil, 1991, 2000 e 2010

\begin{tabular}{llrcr}
\hline \hline Ano & Convenção & $I$ de Moran & $\mathrm{E}(I)$ & $p$-value \\
\hline \multirow{2}{*}{1991} & Rainha & 0,3393 & $-0,0002$ & 0,0010 \\
& Torre 6 vizinhos & 0,3392 & $-0,0002$ & 0,0010 \\
& K 8 vizinhos & 0,2871 & $-0,0002$ & 0,0010 \\
& K 10 vizinhos & 0,2749 & $-0,0002$ & 0,0010 \\
\hline \multirow{2}{*}{ Rainha } & 0,3212 & $-0,0002$ & 0,0010 \\
& Torre & 0,3214 & $-0,0002$ & 0,0010 \\
& K 6 vizinhos & 0,2822 & $-0,0002$ & 0,0010 \\
& K 8 vizinhos & 0,2722 & $-0,0002$ & 0,0010 \\
& K 10 vizinhos & 0,2616 & $-0,0002$ & 0,0010 \\
\hline \multirow{2}{*}{ Rainha } & 0,2517 & $-0,0002$ & 0,0010 \\
& Torre & 0,2519 & $-0,0002$ & 0,0010 \\
K 6 vizinhos & 0,2446 & $-0,0002$ & 0,0010 \\
& K 8 vizinhos & 0,2359 & $-0,0002$ & 0,0010 \\
K 10 vizinhos & 0,2280 & $-0,0002$ & 0,0010 \\
\hline \hline
\end{tabular}

Fonte: Elaboração própria a partir dos resultados da pesquisa.

Para a escolha da matriz de pesos espaciais, foi verificado o valor do $I$ de Moran. Desse modo, foi possivel observar que a matriz de convenção Rainha apresentou o maior valor apenas no ano de 1991. A matriz Torre apresentou o melhor $I$ de Moran em dois anos, mas com valores muito semelhantes da matriz Rainha. Dado o argumento de Almeida (2012), de que a matriz de pesos espaciais apresenta o grau de conectividade entre as regiões, a matriz utilizada nesse trabalho foi a convenção Rainha, pois apresenta maior possibilidade de capturar a autocorrelação espacial do fluxo migratório, pois pode considerar até 8 vizinhos, diferentemente da matriz Torre, que pode considerar no máximo 4 vizinhos.

Para a análise local, busca-se identificar os padrões de associação espacial por meio do $I$ de Moran local. Por sua vez, na figura a seguir, é apresentado o mapa de clusters LISA, que representa a combinação das informações do diagrama de dispersão e do mapa de significância das medidas de associação local. Foi possível observar na figura que, de maneira geral, essa análise sugere um alto nível de dependência espacial para os fluxos migratórios, porém houve redução da dependência espacial 
no período. Em 1991, a taxa líquida de migração apresentava 364 (9\%) municípios em clusters Alto-Alto e 839 (20\%) municípios em clusters Baixo-Baixo. Esses clusters, para o ano 2000, correspondem cada a 9\% e $24 \%$ dos municípios e, por sua vez, em 2010 , correspondem a $8 \%$ e 19\% dos municípios, respectivamente.

Deve ser destacado que os clusters espaciais dos municípios com alto fluxo migratório cercados por municípios com alta taxa de migração líquida estão localizados principalmente no estado de São Paulo e na região Centro-Oeste, e os agrupamentos espaciais de municípios com baixa taxa de migração cercadas por municípios que também apresentam baixo indicador de migração então situados principalmente na região Nordeste e no estado de Minas Gerais.

Em uma análise mais detalhada para o ano de 1991 por Unidade da Federação para São Paulo e para a região Centro-Oeste, é possivel verificar que as unidades federativas em que mais se concentraram municípios no agrupamento Alto-Alto foram São Paulo, Distrito Federal e Mato Grosso do Sul, os quais apresentaram a maior concentração de municípios nesse cluster. No ano 2000, houve um aumento da concentração de aglomerações com alto fluxo migratório nos municípios na região Centro-Oeste. Na análise por Unidade da Federação, os estados com as maiores concentrações de municípios foram São Paulo e Mato Grosso do Sul. Por sua vez, no ano de 2010, novamente houve um aumento em relação ao ano 2000 da concentração de aglomerações de municípios com essa característica na região Centro-Oeste. Na análise por Unidade da Federação, Mato Grosso e Mato Grosso do Sul foram os estados que apresentaram maior concentração de municípios com alta taxa de migração no período.

Figura 3. Mapa de cluster LISA dos índices da MIGRA no Brasil, 1991, 2000 e 2010
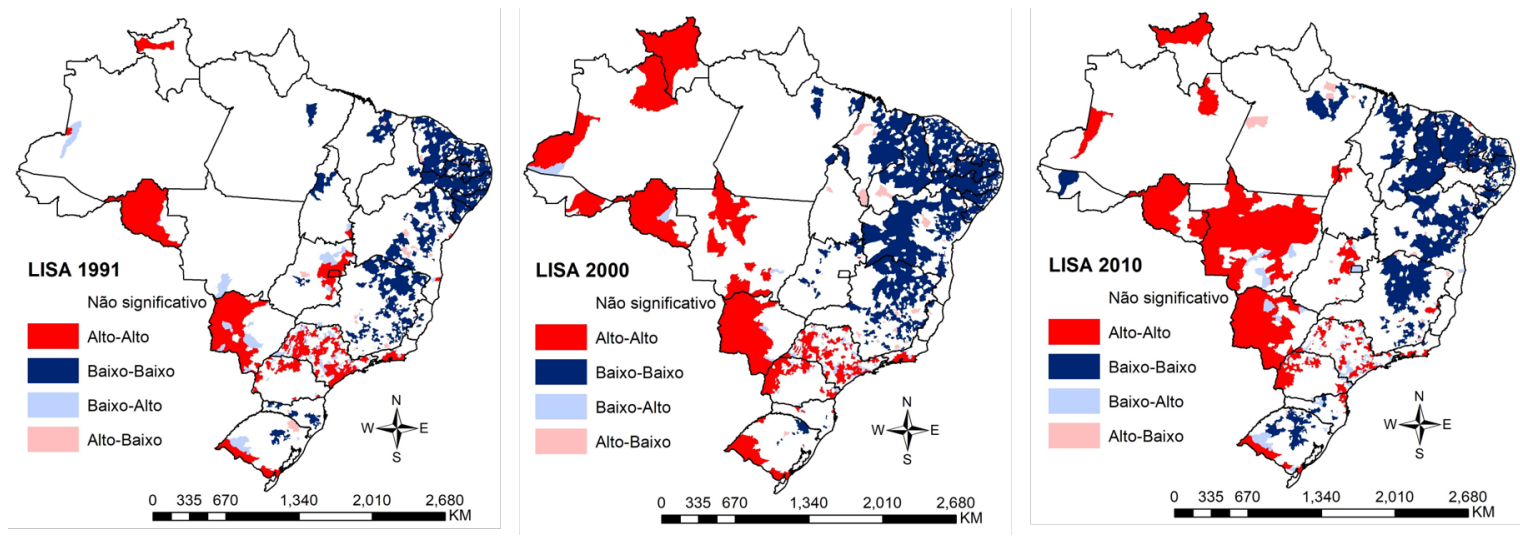

Fonte: Elaboração própria a partir dos dados da pesquisa.

Para a análise do cluster Baixo-Baixo no estado de Minas Gerais e na região Nordeste por Unidade da Federação para o ano de 1991, destacam-se os estados do Ceará, Rio Grande do Norte, Paraíba, Pernambuco, Alagoas e Sergipe com as maiores concentrações dos municípios nos clusters com baixa taxa de migração. Entre os anos 1991 e 2000, houve elevação na concentração de municípios com baixo fluxo migra- 
tório em Minas Gerais e na região Nordeste. Na análise por Unidade da Federação, no ano 2000, todos os estados da região Centro-Oeste apresentaram destaque, com mais de $40 \%$ de municípios nessa aglomeração com baixa taxa de migração. Já no ano de 2010, houve redução em relação ao ano 2000 na concentração de municípios nesse cluster. Por meio da análise por Unidade da Federação, em 2010, pode ser observado que os estados que se destacaram nessa aglomeração foram Piauí, Ceará, Rio Grande do Norte, Paraíba, Alagoas e Sergipe, os quais apresentam maior percentual de municípios em aglomerações com baixo fluxo migratório.

Os altos fluxos migratórios na região Centro-Oeste e no estado de São Paulo podem ocorrer por serem localidades que apresentam municipios com mais oportunidades de emprego e melhor qualidade de vida. São Paulo, em todo o período, apresentou destaque com altas taxas de migração líquida, já a região Centro-Oeste ganhou destaque no período e um dos fatores que pode explicar esse fator foi o desenvolvimento no período ocasionado pelo crescimento do agronegócio na região, o que levou o estado a apresentar uma redução da desigualdade na distribuição de renda. Conforme mostra o estudo de Cunha e Vasconcelos (2012), a região Sudeste apresentou, em 1995, o maior salário médio entre as regiões e o segundo maior em 2009, e a região CentroOeste, apesar de apresentar o segundo menor salário em 1995, em 2009 alcançou o maior salário médio entre as regiões, com aumento de quase $20 \%$ no período.

Por outro lado, a região Nordeste e o estado de Minas Gerais, apesar da melhora nos indicadores de fluxo migratório no período, não são os lugares mais procurados pelo baixo desenvolvimento da região, tanto pelo solo quanto pelo baixo investimento industrial. Desse modo, a região Nordeste e o estado de Minas Gerais e a região Centro-Oeste e o estado de São Paulo se enquadram nos fatores "push" e "pull", respectivamente, pois, conforme Golgher et al. (2004), a migração é caracterizada por uma baixa qualidade de vida no local de origem (região Nordeste e estado de Minas Gerais) e um melhor nível de vida no local de destino (região Centro-Oeste e estado de São Paulo).

Para realizar uma investigação mais detalhada dos fatores que motivam os indivíduos a migrarem, na próxima seção, verificou-se o impacto da desigualdade na distribuição de renda e da pobreza multidimensional (que considera fatores de qualidade de vida, privações nas dimensões de saúde e saneamento, educação, condições de habitação, trabalho, renda e demografia) sobre os fluxos migratórios nos municípios brasileiros.

\section{Determinantes dos fluxos migratórios no Brasil}

Nesta seção, foram apresentadas e discutidas as estimativas dos modelos econométricos, buscando identificar os determinantes dos fluxos migratórios nos municípios brasileiros. Inicialmente, foram apresentadas as estatísticas descritivas das variáveis independentes para a média dos anos de 1991, 2000 e 2010. Posteriormente, 
foram apresentadas as estimativas dos modelos considerando o modelo de Mínimos Quadrados Ordinários (MQO) para os dados empilhados, de painel de dados de efeitos fixos (sem dependência espacial) e de painel de dados de efeitos fixos com dependência espacial para a Taxa Líquida de Migração (MIGRA). Posteriormente, também foram realizadas outras estimações para verificar a robustez dos coeficientes.

Na tabela a seguir, podem ser observadas as estatísticas descritivas das variáveis independentes do modelo para a média dos três anos. Pode ser observado que as variáveis taxa de urbanização (TX_URB), densidade populacional (DENS_POP), proxy da distância inversa da capital ponderada pelo PIB (DISTÂNCIA) e renda domiciliar per capita (REND_D_PC) apresentaram alta dispersão dos dados.

Tabela 2. Estatísticas descritivas das variáveis explicativas do modelo, Brasil, 1991, 2000 e 2010

\begin{tabular}{lrrrrr}
\hline \hline \multicolumn{1}{c}{ Variável } & Média & Mínimo & Máximo & Desvio-padrão & $\begin{array}{c}\text { Coeficiente } \\
\text { de variação (\%) }\end{array}$ \\
\hline TX_URB & 0.5976 & 0.0000 & 1.0000 & 0.2266 & 37.93 \\
DENS_POP & 109.4288 & 0.0896 & 13142.4900 & 579.3397 & 529.42 \\
DISTANCIA & 0.1532 & 0.0000 & 1.0000 & 0.2002 & 130.67 \\
REND_D_PC & 0.3058 & $6.7 \mathrm{e}-06$ & 2.7844 & 0.2594 & 84.81 \\
IPM & 0.3116 & 0.1493 & 0.5428 & 0.0927 & 29.75 \\
GINI & 0.5067 & 0.1058 & 0.9283 & 0.0786 & 15.52 \\
\hline \hline
\end{tabular}

Fonte: Elaboração própria a partir dos resultados da pesquisa.

A estimativa de painel de dados possui tanto a dimensão de corte transversal, quanto a dimensão temporal, elevando assim os graus de liberdade e, por consequência, aumentando a eficiência do estimador (Greene, 2000; Elhorst, 2014).

Foi estimado o modelo Pooled para os dados empilhados e, conforme sugere Almeida (2012), foi verificado, por meio do teste Breusch-Pagan, se existem efeitos não observados no modelo. Como o valor do teste foi significativo, é necessário utilizar o modelo de painel de dados. Greene (2000); Elhorst (2014) ainda sugerem que, para verificar qual o modelo de painel de dados mais adequado, o modelo de efeitos fixos ou o modelo de efeitos aleatórios, deve-se realizar o teste de Hausman. Dado que foi rejeitada a hipótese de efeitos aleatórios, o modelo apresentado foi com efeitos fixos (FE).

Após a escolha do modelo, é recomendado verificar se existe heterogeneidade espacial, ou seja, autocorrelação espacial nos resíduos para verificar se existe a necessidade de se incluírem efeitos espaciais no modelo. Posteriormente à estimação de painel de dados de efeitos fixos, foi verificada a dependência espacial dos resíduos por 
meio do $I$ de Moran para os três anos. Desse modo, foi apropriado usar os modelos de painel de dados de efeitos fixos com dependência espacial.

Foi observado que apenas o modelo SLX corrigiu a autocorrelação espacial nos resíduos. Desse modo, não foi necessário utilizar o teste LIK e os critérios de informação de AIC e BIC para a escolha do modelo, sendo assim, o modelo mais adequado foi o SLX. Posteriormente à escolha do modelo, observa-se, na tabela a seguir, que foram estimadas todas as variáveis, sendo que nas seis primeiras foram incluídas as dimensões individuais do índice de pobreza multidimensional, na sétima especificação, foram incluídas todas as especificações e a última dimensão é referente ao modelo com o Îndice de Pobreza Multidimensional.

Na especificação com a dimensão renda, o impacto foi negativo e significativo sobre a migração, e, nas especificações das demais dimensões, o impacto também foi negativo e significativo sobre os fluxos migratórios (com exceção da dimensão demografia). $\mathrm{Na}$ especificação com todas as dimensões, a dimensão renda apresentou impacto positivo sobre a migração, as dimensões saúde e saneamento e educação apresentaram impacto negativo, enquanto as demais dimensões não apresentaram impactos significativos. Na última especificação, o impacto foi o esperado, negativo e significativo, devendo ser destacado que foi a única especificação que corrigiu a heterogeneidade espacial.

Desse modo, conforme apresentado no modelo VIII, entre as variáveis de interesse, o Índice de Pobreza Multidimensional apresentou impacto negativo sobre a taxa de migração, ou seja, quanto maior a pobreza multidimensional, menor o fluxo migratório. Isso pode ser explicado pelo fato de que os indivíduos tendem a procurar uma melhor qualidade de vida e melhor perspectiva econômica, e a pobreza multidimensional abrange diversos fatores que estão relacionados à qualidade de vida e à renda, sendo que as variáveis são referentes à privação nas áreas de saúde e saneamento, educação, condição de habitação, trabalho, renda e demografia. Quanto maior o indicador de pobreza multidimensional, maiores são as privações e menor é a atração de imigrantes.

O índice de Gini também apresentou impacto negativo em relação à taxa de migração, um aumento da concentração de renda colabora para reduzir os fluxos migratórios. Uma desigualdade na distribuição de renda alta indica que poucos detêm grande parte da renda. Assim, aqueles que desejam obter melhores condições econômicas para atender pelo menos suas necessidades básicas, tenderam a procurar municípios com menor desigualdade, pois a renda está mais distribuída. Desse modo, quanto maior a desigualdade de renda, maior o fluxo migratório. 


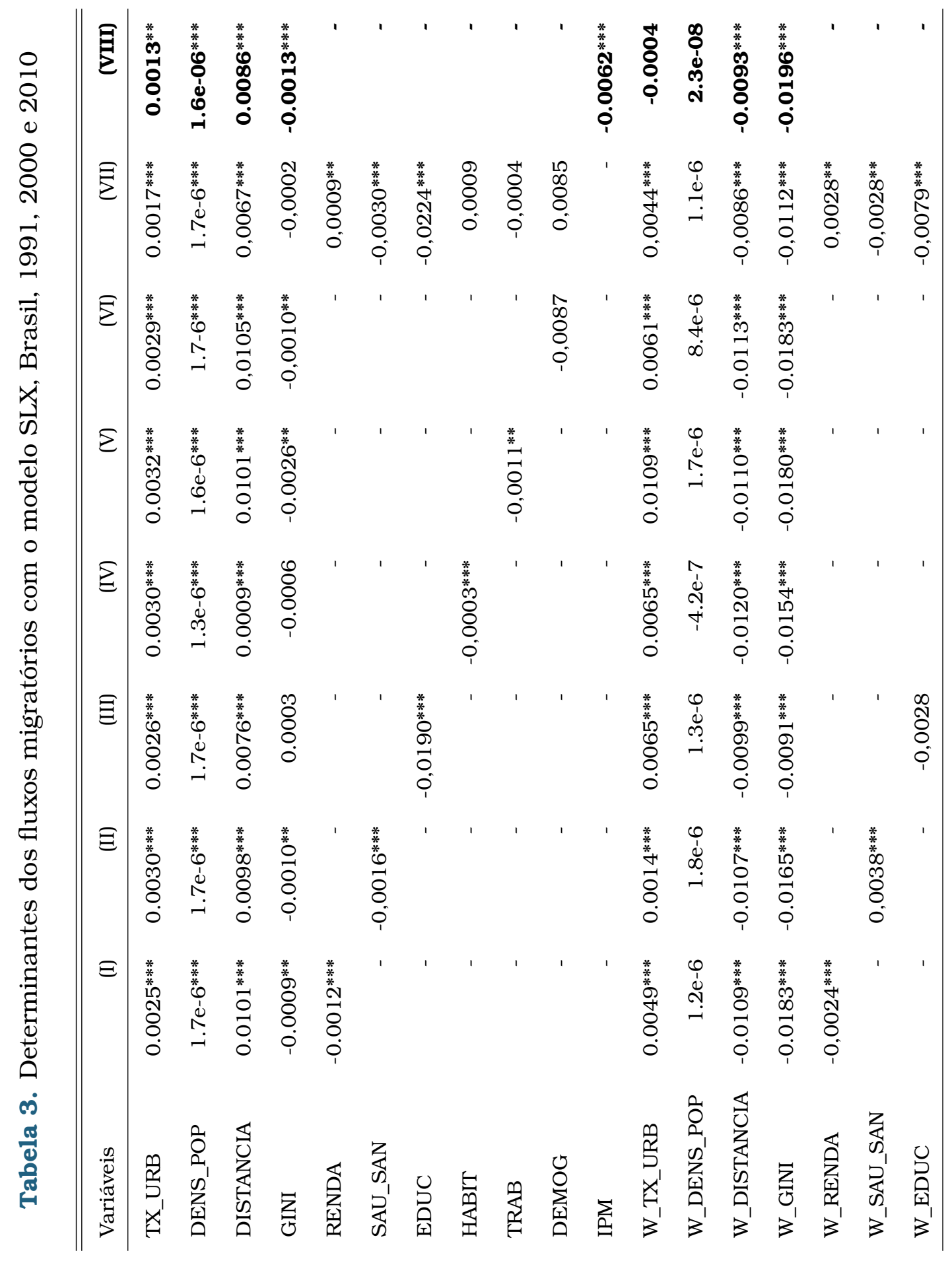




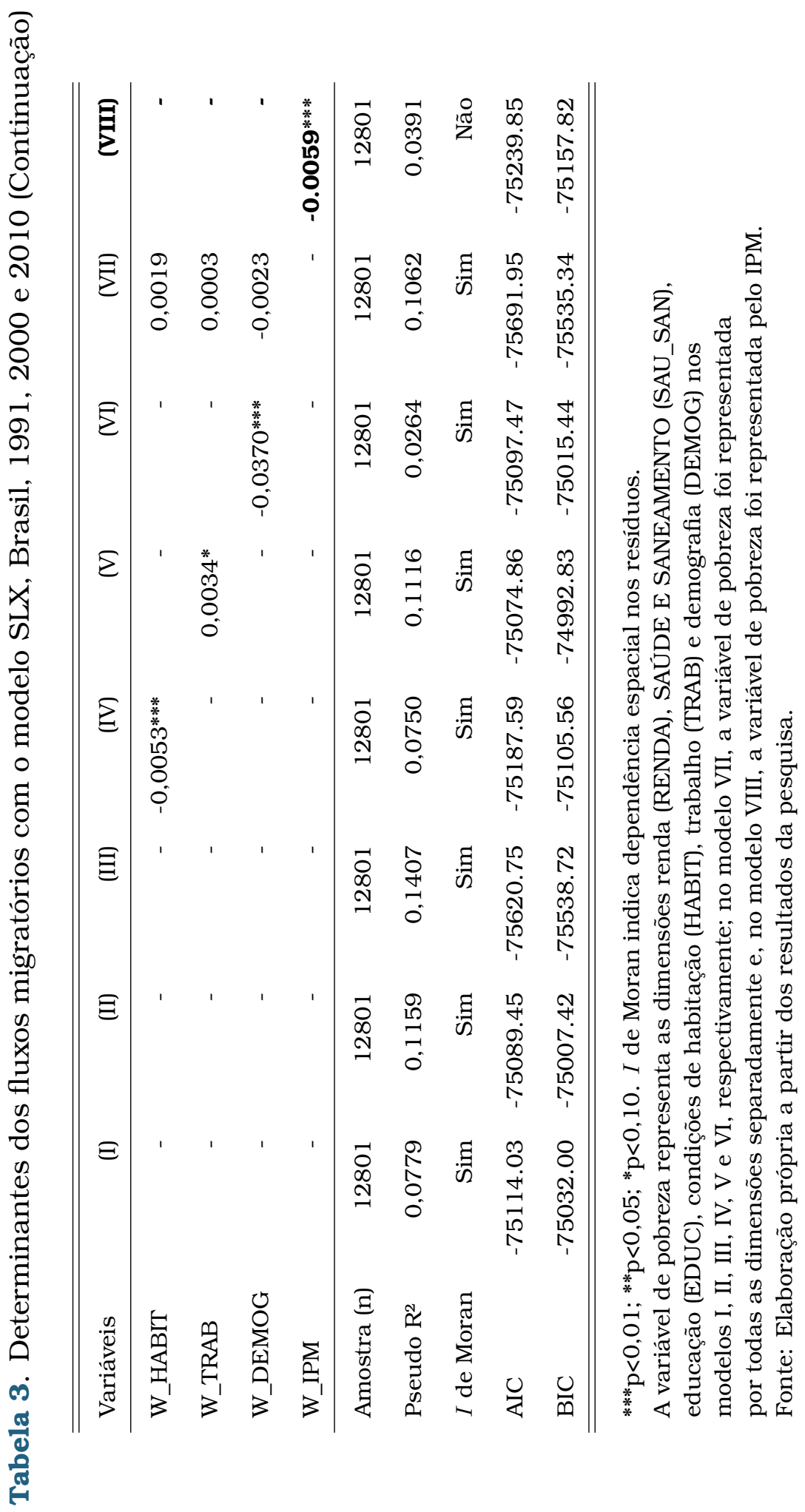


Em relação às variáveis de interesse dos municípios vizinhos, o impacto das defasagens espaciais da pobreza multidimensional e da desigualdade na distribuição de renda foram negativos, indicando que um aumento na pobreza multidimensional e na concentração de renda dos municípios vizinhos reduz a taxa de migração.

Quanto às outras variáveis explicativas, a taxa de urbanização apresentou impacto positivo sobre a taxa de migração, ou seja, quanto maior o percentual da população que vive na área urbana, maior o fluxo migratório. Os indivíduos procuram mais áreas urbanizadas por apresentarem mais oportunidades do que na área rural. Nas cidades, há maiores chances de o indivíduo conseguir emprego, além de ter mais acesso aos serviços públicos como saúde e educação. Desse modo, os municípios mais urbanos tendem a atrair mais imigrantes.

Da mesma forma que a taxa de urbanização sugere maiores oportunidades, a densidade populacional também apresentou impacto positivo sobre taxa de migração, ou seja, um aumento do número de pessoas por quilômetro quadrado contribui para um aumento do fluxo migratório. A distância inversa da capital ponderada pelo PIB apresentou impacto positivo em relação à taxa de migração. Desse modo, quanto menor a distância do município das capitais mais ricas, maior o fluxo migratório.

No que concerne às defasagens espaciais das outras variáveis explicativas, o impacto da distância inversa da capital ponderada pelo PIB foi negativo, indicando que um aumento na distância de capitais mais ricas dos municípios vizinhos acarreta um aumento no fluxo migratório. Guanto à defasagem espacial da taxa de urbanização e da densidade populacional, os dados não foram significativos.

Os resultados também apontaram que a taxa de urbanização, a densidade populacional e a distância inversa da capital ponderada pelo PIB apresentam impacto positivo sobre a taxa de migração. Isso porque áreas mais urbanizadas, com mais pessoas por quilômetro quadrado e mais próximas da capital tendem a ser mais desenvolvidas, mais ricas e com mais oportunidades para o indivíduo gerar renda, além de proporcionar mais acesso à saúde, à educação e a programas sociais (Sahota, 1968; Pekkala, 2003; Justo e Silveira Neto, 2006; Da Mata et al., 2008; Kim e Cohen, 2010; Mayda, 2010; Ramalho e Gueiroz, 2011; Etzo, 2011; Maciel e Cunha, 2013; Gama e Machado, 2014).

Por outro lado, o índice de Gini contribuiu para a redução dos fluxos migratórios, pois um dos principais fatores que levam o indivíduo a migrar é por questões econômicas, por isso os destinos que tendem a ser procurados são aqueles que apresentam uma maior distribuição de renda, resultado que corrobora os trabalhos de Sahota (1968); Borjas (1987); Justo e Silveira Neto (2006); Da Mata et al. (2008).

O trabalho de Kim e Cohen (2010) indicou que quanto maior a mortalidade infantil, menor é a taxa de migração, variável relacionada com a dimensão saúde e saneamento. Quanto à dimensão educação, os trabalhos de Pekkala (2003); Da Mata et al. (2008); Gama e Machado (2014) apontaram que a educação favorece a migração 
no destino. Para a dimensão condições de habitação, os estudos de Pekkala (2003) sugerem que localidades com condições habitacionais mais precárias são menos procuradas pelos migrantes. Para a dimensão trabalho, os estudos de Sahota (1968); Hunt (2006); Da Mata et al. (2008); Etzo (2011) indicam que quanto maior for o salário ou menor a taxa de desemprego, maior será a atração de migrantes, sendo que um dos principais fatores que pode ter atraído imigrantes para o estado de São Paulo e para a região Centro-Oeste foi o salário, pois, como indica o trabalho de Cunha e Vasconcelos (2012), as regiões Centro-Oeste e Sudeste apresentam os maiores salários médios.

Ademais, levando em conta a heterogeneidade espacial dos municípios brasileiros para explicar a Taxa Líquida de Migração, foram considerados os efeitos espaciais dos municípios brasileiros, conforme indica a literatura empírica, especialmente a concentração de renda e a pobreza multidimensional dos municípios vizinhos.

Desse modo, os resultados sugerem que a desigualdade na distribuição de renda e a pobreza multidimensional apresentaram impacto negativo sobre a migração municipal interestadual. Ou seja, melhores perspectivas econômicas e menores privações nas dimensões saúde e saneamento, educação, condições de habitação, trabalho, renda e demografia contribuem para a atração de migrantes para o município. Verificaram-se também os efeitos de transbordamento dos fluxos migratórios para os municípios brasileiros.

\section{Considerações finais}

Nesse trabalho, foi construída a Taxa Líquida de Migração para os municípios nos anos de 1991, 2000 e 2010, buscando analisar a distribuição espacial dos fluxos migratórios nos municípios brasileiros considerando as Áreas Minimamente Comparáveis (AMC) e o impacto da pobreza e da desigualdade na distribuição de renda nos fluxos migratórios nos anos de 1991, 2000 e 2010. Foram considerados os 4267 municípios para o ano de 1991 e foram verificadas as regiões com maiores e menores concentrações de migrantes.

Uma das contribuições deste estudo foi a estimação das migrações interestaduais por município do Brasil. Além disso, o trabalho inova em apontar o impacto negativo da pobreza multidimensional sobre a taxa de migração, ou seja, municípios com menores privações nas áreas de saúde e saneamento, educação, condições de habitação, trabalho, renda e demografia tendem a ser os destinos mais procurados pelos migrantes por serem localidades com maior qualidade de vida, por apresentarem melhores perspectivas econômicas, mais oportunidades de trabalho, melhor nível educacional e melhores condições de saúde, saneamento e habitação. Essas concepções estão em consonância com os resultados da literatura.

Os resultados apontaram dependência espacial nos três anos, ou seja, municípios com altas (baixas) taxas de migração são circunvizinhados por municípios com altas 
(baixas) taxas de migração, sendo que a concentração de municípios com altas taxas de migração se situa principalmente no estado de São Paulo e na região Centro-Oeste e as aglomerações de municípios com baixas taxas de migração estão localizadas principalmente no estado de Minas Gerais e na região Nordeste.

As altas concentrações de fluxos migratórios na região Centro-Oeste e no estado de São Paulo podem ocorrer por essas serem regiões que apresentam municípios com mais oportunidades de emprego e melhor qualidade de vida. São Paulo, em todo o período, apresentou destaque com altas taxas de migração líquida, já a região CentroOeste ganhou destaque no período, e um dos fatores que podem explicar esse fato foi o desenvolvimento no período ocasionado pelo crescimento do agronegócio na região, o que levou o estado a apresentar uma redução da desigualdade na distribuição de renda.

Por outro lado, a região Nordeste e o estado de Minas Gerais, mesmo com a melhora no fluxo migratório no período, não são os lugares mais atrativos pelo baixo desenvolvimento da região, tanto pelo solo quanto pelo baixo investimento industrial. Desse modo, a região Nordeste e o estado de Minas Gerais e a região Centro-Oeste e o estado de São Paulo se enquadram nos fatores "push" e "pull", respectivamente, pois a migração pode ser caracterizada por uma baixa qualidade de vida no local de origem (região Nordeste e estado de Minas Gerais) e um melhor nivel de vida no local de destino (região Centro-Oeste e estado de São Paulo).

Com base nas estimativas do modelo para dados de painel com dependência espacial, é possivel observar que as variáveis de interesse, pobreza multidimensional e desigualdade na distribuição de renda, apresentaram impacto negativo sobre a taxa de migração e, ainda, o impacto da pobreza multidimensional foi maior do que a desigualdade na distribuição de renda. A qualidade de vida apresenta maior influência na decisão de o indivíduo migrar. Além disso, deve ser destacado que a grande contribuição deste estudo é evidenciar o impacto da pobreza em um aspecto multidimensional, que mostra que municípios com menores privações nas áreas de saúde e saneamento, educação, condições de habitação, trabalho, renda e demografia tendem a ser os destinos mais procurados pelos migrantes, por serem localidades com maior qualidade de vida.

Os demais resultados das estimativas indicaram que as variáveis taxa de urbanização, densidade populacional e distância inversa da capital ponderada pelo PIB apresentaram impacto positivo sobre os fluxos migratórios, isso pode indicar que a relação de densidade populacional pode ser explicada pelos imigrantes anteriores, que conseguiram se inserir no mercado de trabalho, e, assim, a cidade atrai novos imigrantes, pois é possivel que o município esteja localizado em uma região de polo industrial; enquanto a relação da distância inversa da capital ponderada pelo PIB pode indicar que essa relação tende a ser maior nas capitais ou nos municípios próximos às capitais, principalmente as mais ricas como São Paulo, pois apresentam mais oportunidades de emprego que no interior, pela grande quantidade de indústrias e do 
comércio em geral.

Por outro lado, as variáveis defasadas no espaço, distância inversa da capital ponderada pelo PIB dos municípios vizinhos, pobreza multidimensional dos municípios vizinhos e desigualdade na distribuição de renda dos municípios vizinhos, apresentaram impacto negativo sobre a taxa de migração. Em relação aos municípios vizinhos, o maior impacto foi de desigualdade na distribuição de renda, representando um fator preponderante na decisão de o indivíduo migrar.

Foi possivel observar que os indivíduos migram para localidades com melhor qualidade de vida e melhor perspectiva econômica. Dessa forma, podem ser formuladas políticas que atendam às demandas da população para que possam ter melhores condições de vida, com investimento nas áreas de saúde, educação e infraestrutura, e políticas de geração de emprego, especialmente na região Nordeste e no estado de Minas Gerais, que apresentam, pela análise espacial, o menor interesse dos indivíduos em migrar. Assim, o trabalho mostrou municipios que apresentam menos atrativos para a migração, ou seja, com baixo bem-estar da população, com isso, é possível focar nas políticas, especialmente, nesses municípios, não apenas para atrair imigrantes, mas também para melhorar a qualidade de vida e as perspectivas econômicas da população.

\section{Referências}

Abreu, M. e Lago, L. A. C. (2010). A economia brasileira no Império, 1822-1889. In: A Ordem do Progresso: dois séculos de politica econômica no Brasil.

Albuquerque, M. R. e Cunha, M. S. (2012). Uma análise da pobreza sob o enfoque multidimensional no Paraná. Revista de Economia, 38(3):45-64.

Almeida, E. (2012). Econometria espacial. Campinas-SP. Alínea.

Andrade, E., Laurini, M., Madalozzo, R., e Pereira, P. L. V. (2004). Convergence clubs among Brazilian municipalities. Economics Letters, 83(2):179-184.

Anselin, L. (1995). Local Indicators of Spatial Association-LISA. Geographical analysis, 27(2):93-115.

Anselin, L. (2013). Spatial econometrics: methods and models, volume 4. Springer Science \& Business Media.

Borjas, G. J. (1987). Self-selection and the earnings of immigrants. Texto para Discussão 2248, National Bureau of Economic Research.

Coelho, R. L. P. e Figueiredo, L. d. (2007). Uma análise da hipótese da convergência para os municípios brasileiros. Revista Brasileira de Economia, 61(3):331-352.

Cooper, J. M. R. (1994). Migration and market wage risk. Journal of Regional Science, 34(4):563-582. 
Cunha, M. S. e Vasconcelos, M. R. (2012). Evolução da desigualdade na distribuição dos salários no Brasil. Economia Aplicada, 16(1):105-136.

Cushing, B. e Poot, J. (2004). Crossing boundaries and borders: Regional science advances in migration modelling. Papers in Regional Science, 83(1):317-338.

Da Mata, D., de Albuquerque Oliveira, C. W., Pin, C., e Resende, G. (2008). Migração, qualificação e desempenho das cidades brasileiras. In: Dinâmica dos Municípios, Página 289-322. Brasília: IPEA.

Druska, V. e Horrace, W. C. (2004). Generalized moments estimation for spatial panel data: Indonesian rice farming. American Journal of Agricultural Economics, 86(1):185-198.

Elhorst, J. P. (2014). Spatial econometrics: from cross-sectional data to spatial panels. Springer.

Etzo, I. (2011). The determinants of the recent interregional migration flows in Italy: A panel data analysis. Journal of Regional Science, 51(5):948-966.

Favero, E. (2004). Desmembramento territorial: o processo de criação de municípiosavaliação a partir de indicadores econômicos e sociais. Tese de Doutorado, Universidade de São Paulo.

Gama, L. C. D. e Machado, A. F. (2014). Migração e rendimentos no Brasil: análise dos fatores associados no periodo intercensitário 2000-2010. Estudos Avançados, 28(81):155-174.

Golgher, A. B. et al. (2004). Fundamentos da migração. Belo Horizonte: UFMG/Cedeplar.

Greene, W. H. (2000). Econometric analysis. New Jersey: Prentice Hall.

Hunt, J. (2006). Staunching emigration from East Germany: Age and the determinants of migration. Journal of the European Economic Association, 4(5):1014-1037.

Justo, W. R. e Silveira Neto, R. d. M. (2006). Migração inter-regional no Brasil: evidências a partir de um modelo espacial. Revista Economia, 7(1):163-187.

Kim, K. e Cohen, J. E. (2010). Determinants of international migration flows to and from industrialized countries: A panel data approach beyond gravity. International Migration Review, 44(4):899-932.

LeSage, J. P. e Pace, R. K. (2014). Introduction to spatial econometrics. New York: CRC Press.

Maciel, F. T. e Cunha, M. S. (2013). Migração e diferenciais de rendimento no brasil: uma análise sobre o efeito do tempo de chegada ao local de destino. Revista Econômica do Nordeste, 44(3):627-650. 
Magalhães, J. C. (2007). Emancipação político-administrativa de municípios no Brasil. In: Dinâmica dos municípios. Brasília: IPEA.

Massey, D. S. (1999). International migration at the dawn of the twenty-first century: The role of the state. Population and Development Review, 25(2):303-322.

Mayda, A. M. (2010). International migration: A panel data analysis of the determinants of bilateral flows. Journal of Population Economics, 23(4):1249-1274.

Mueser, P. (1989). The spatial structure of migration: An analysis of flows between states in the USA over three decades. Regional Studies, 23(3):185-200.

Olesen, H. (2002). Migration, return, and development: An institutional perspective. International migration, 40(5):125-150.

Pace, R. K. e Zhu, S. (2012). Separable spatial modeling of spillovers and disturbances. Journal of Geographical Systems, 14(1):75-90.

Pekkala, S. (2003). Migration flows in Finland: Regional differences in migration determinants and migrant types. International Regional Science Review, 26(4):466482 .

Ramalho, H. M. d. B. e Gueiroz, V. d. S. (2011). Migração interestadual de retorno e autosseleção: evidências para o Brasil. Pesquisa e Planejamento Econômico, 41(3):369396.

Sahota, G. S. (1968). An economic analysis of internal migration in Brazil. Journal of Political Economy, 76(2):218-245.

Simoes, C. C. d. S. (2016). Relações entre as alterações históricas na dinâmica demográfica brasileira e os impactos decorrentes do processo de envelhecimento da população, Página 98-119. Rio de Janeiro: IBGE, Coordenação de População e Indicadores Sociais.

Sjaastad, L. A. (1962). The costs and returns of human migration. Journal of Political Economy, 70(5, Part 2):80-93.

@Ev Este artigo está licenciado com uma CC BY 4.0 license. 